\title{
Paul Dollfus
}

\author{
Wyndaele Jean Jacques ${ }^{1} \cdot$ Wagih El-Masri(y) ${ }^{2}$
}

Received: 22 July 2019 / Accepted: 22 July 2019 / Published online: 13 August 2019

(c) International Spinal Cord Society 2019

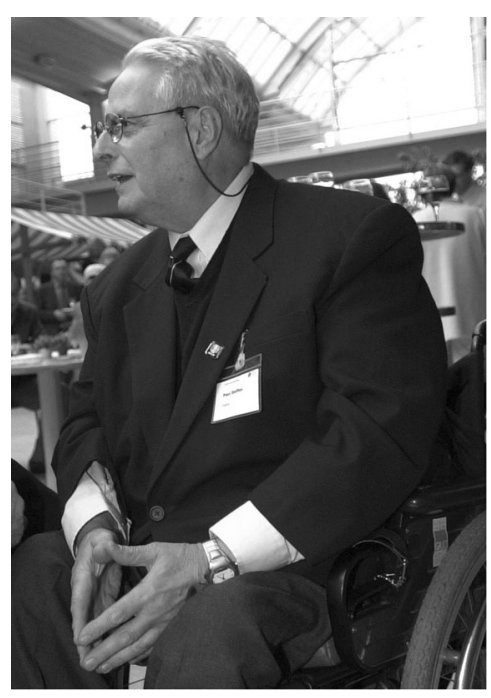

It is with great sadness that we received news of the death of Prof. Paul Dollfus. He was born in 1929, the son of a French father and an Irish mother. He studied medicine with great dedication and passion. At age 25, he contracted poliomyelitis which left him with serious neurologic sequelae. This may have encouraged him to choose the field of functional rehabilitation which took him to the world famous National Spinal Injuries Centre at Stoke Mandeville, Aylesbury, UK. He was trained by one of the Fathers of modern SCI Management Sir Ludwig Gutmann. Guttmann inspired him to develop a holistic approach to all the medical, physical and nonmedical effects of cord damage rather than just focus on the paralysis. Paul met his wife Barbro, the love of his life, at Stoke Mandeville. They have since embarked on

Wagih El-Masri(y)

bellstonehse@btinternet.com

1 Department of Urology, University of Antwerp, Edegem, Belgium

2 The Robert Jones and Agnes Hunt Orthopaedic Hospital, Keele University, Institute of Orthopaedics, Oswestry, Shropshire, UK their journey of many years of happy and devoted life together. Paul and Barbro have two daughters Hélène and Patricia. Paul adored, supported and encouraged his daughters who were blessed by his love and that of their mother. When he returned to France, Paul became Head Physician of the rehab centre of Mulhouse, a position he held for more than 30 years. He was an impressive energetic generous and caring 'boss' and his generosity and charisma made him an unforgettable individual to all those who knew him, worked for him and taught by him. The Mulhouse centre became a well-known Centre of excellence with an international reputation for excellent care and good research. Paul's networking was truly international; he had close friends all across the globe. He was never deterred by physical or other barriers and always managed to get across where he wanted to. He fought hard for the full recognition of the rights and abilities of the handicapped individual. He achieved recognition as Specialist in Physical Medicine and Rehabilitation from the moment this title was created.

In 1961, he was a Founding Member of the IMSoP, now named ISCoS, and held many offices in the group, becoming its President from 1992 till 1996. Paul was a member and Executive Officer of several scientific organisations, and was active in the UN, OMS, EU committees. His list of publications is extensive, and he was awarded several important prizes and honours.

His personal life showed interest in a variety of fields from Fly Fishing, to trains and more. His grandchildren gave him a lot of joy and he always followed their growing with lovely attention.

Paul was our friend. To visit him and Barbro in their lovely house in Mulhouse were highlights of our travels to France.

Paul was known as the "Grand Sage" an honourable title that represented his wisdom, common sense and his humour as well as his readiness to give sound advice and help any time.

We know many of us will remember Paul, his cheerful character and witty smites for many years to come. 